\title{
A COMPARATIVE STUDY OF COMPUTED TOMOGRAPHIC ANGIOGRAPHY AND DIGITAL SUBTRACTION ANGIOGRAPHY IN EVALUATION OF ANEURYSMAL SUBARACHNOID HAEMORRHAGE
}

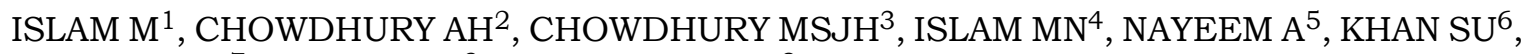 \\ RAHMAN KM ${ }^{7}$, SARKAR RN ${ }^{8}$, MOHAMMAD QD ${ }^{9}$
}

\begin{abstract}
Context: The aim of the study was to retrospectively analyze the performance of Computed Tomographic Angiography (CTA) in detecting, localizing and sizing intracranial aneurysms in patients of aneurysmal subarachnoid haemorrhage using Digital Subtraction Angiography (DSA) as standard.
\end{abstract}

\begin{abstract}
Methods: The study was carried out from December 2009 to November 2010 in the Dept. of Neurology of Dhaka Medical College Hospital, Dhaka. Among 81 patients of SAH admitted in the above mentioned period, 30 were enrolled in the study as they met the inclusion criteria. Patient's age range was 26 to 70 years; male female ratio was 1.5: 1 . All the study patients underwent both DSA and CTA examinations. The findings of both procedures were recorded and compared.
\end{abstract}

\begin{abstract}
Results: A total of 30 aneurysms in 30 patients were identified on DSA. Among 10 small sized aneurysms $(<4 \mathrm{~mm})$ detected by DSA, CTA incorrectly diagnosed 2 and overlooked 2 aneurysms. Out of 14 medium sized (5- $12 \mathrm{~mm}$ ) identified on DSA, CTA missed 2 aneurysms. But CTA correctly diagnosed all 6 large $(e " 13 \mathrm{~mm})$ aneurysms. The overall sensitivity of CTA was $60 \%$ for small, $85.7 \%$ for medium and $100 \%$ for large aneurysm. Regarding identification of aneurysmal sites, CTA correctly localized 22 (73.4\%), incorrectly localized 4 (13.3\%) and missed 4 (13.3\%) cases. Sensitivity of CTA in identification of aneurysmal site was $73.3 \%$.
\end{abstract}

Conclusion: CTA is less sensitive than DSA in detecting small and medium sized aneurysms. However it correlated perfectly with DSA in detection of large aneurysms. The performance of CTA in identification of aneurysmal site is also lesser than DSA. So, DSA remains the standard technique for evaluation of aneurysmal SAH.

J Dhaka Med Coll. 2013; 22(2) : 195-200.

\section{Introduction:}

Subarachnoid hemorrhage (SAH) is the bleeding in the subarachnoid space - the area between the arachnoid mater and the pia mater surrounding the brain. This may occur spontaneously, usually from a ruptured cerebral aneurysm, or may result from head injury ${ }^{1}$. The classic symptoms of subarachnoid hemorrhage are thunderclap headache, a headache described as like being kicked in the head ${ }^{2}$ or the 'worst ever'. The headache from aneurysmal rupture develops in seconds to few minutes ${ }^{3}$. Vomiting occurs in $70 \%$ of patients with aneurysmal rupture and 1 in 14 have seizure ${ }^{4}$. Confusion, decreased level of consciousness or coma may be present. Neck

1. Dr. Mahmudul Islam, Registrar, Clinical Neurology, National Institute of Neurosciences \& Hospital, Dhaka.

2. Dr. Ahmed Hossain Chowdhury, Asst. Professor of Neurology, Dhaka Medical College, Dhaka.

3. Dr. Md Shah Jahirul Hoque Chowdhury, Asst. Professor, Clinical Neurology, National Institute of Neurosciences \& Hospital, Dhaka.

4. Dr. Md Nahidul Islam, Registrar, Neurophysiology, National Institute of Neurosciences \& Hospital, Dhaka.

5. Dr. Abu Nayeem, Registrar, Interventional Neurology, National Institute of Neurosciences \& Hospital, Dhaka.

6. Dr. Sharifuddin Khan, Associate Professor of Neurology, Dhaka Medical College, Dhaka.

7. Dr. Kazi Mohibur Rahman, Assistant Professor, National Institute of Neurosciences \& Hospital, Dhaka.

8. Dr. Rabindranath Sarkar, Associate Professor of Radiology \& imaging, Dhaka Medical College, Dhaka.

9. Prof. Quazi Deen Mohammad, Professor of Neurology, Dhaka Medical College, Dhaka.

Correspondence : Dr. Mahmudul Islam, Registrar, Clinical Neurology, National Institute of Neurosciences \& Hospital, Dhaka. 
stiffness usually presents 6 hours after initial onset of $\mathrm{SAH}^{5}$. Physical examination can provide information about the cause of SAH. Mono ocular blindness may result from anterior communicating artery aneurysm if it is exceptionally large ${ }^{6}$. Complete or partial third nerve palsy is well recognized sign after rupture of an aneurysm of the internal carotid artery at the origin of posterior communicating artery.

If SAH is suspected CT scan of brain is the first line investigation because of the characteristically hyperdense appearance of extravasated blood in the basal cisterns. The pattern of haemorrhage often suggests the location of any underlying aneurysm, although with variable degrees of certainty. DSA is the gold standard in diagnosis of intracranial aneurysm; however the technique is invasive, requires skilled performer, and is relatively costly and time consuming ${ }^{7}$. Among other alternative diagnostic tests, CTA has attracted much attention as a substitute due to its' high accuracy, noninvasive nature, availability and favourable technical aspects as three dimensional, multiplanar imaging, short acquisition time, intravenous rather then intra-arterial contrast ${ }^{7,8}$. Above all, accuracy of $\mathrm{CT}$ angiography has been the foremost consideration because early and definite detection of aneurysm is critical. The purpose of this study is to analyze retrospectively the performance of CTA in detecting, localizing and sizing intracranial aneurysms using conventional intra-arterial DSA in the setting of aneurysmal SAH.

\section{Methods:}

This was a retrospective observational study, which was carried out from December 2009 to November 2010. The study was done in Neurology Department of Dhaka Medical College Hospital (DMCH), Dhaka. All patients of subarachnoid haemorrhage admitted in the Department of Neurology. Total of 81 patients was admitted in the above mentioned period. Sample size was 30. Cerebral aneurysms were evaluated for their location, size and morphology by CTA and DSA. The samples were selected purposively.

\section{Inclusion criteria:}

1. Patients of spontaneous subarachnoid haemorrhage detected clinically and by CT scan.

2. Patients who are capable to do CT angiography \& DSA.

3. Patients who gave consent to take part in the study.

\section{Exclusion criteria:}

1. Traumatic subarachnoid haemorrhage

2. Intra cerebral haemorrhage.

\section{Procedure:}

Data were collected by a semi-structured questionnaire. The patients of subarachnoid haemorrhage were identified on the basis of clinical feature and findings of CT scan of head. Regarding clinical features, detailed history was taken and physical examination was done by the investigator and then it was reviewed by a consultant neurologist before reaching final diagnosis. History of unconscious patients was taken from the attendant. The following information was collected from each patient: age, sex, hypertension, diabetes mellitus, hypercholesterolemia, current or previous smoking, previous incidence of $\mathrm{SAH}$, family history of subarachnoid haemorrhage and family history of kidney disease. Clinical features and examination findings were noted. Detailed drug history was taken. Investigations like $\mathrm{CBC}$, serum lipid profile, blood sugar, serum creatinine, ECG, Chest X-ray were also done. These patients were then sent for CT angiography. The procedure was done in a private clinic and reported by the same radiologist in all cases. Findings were recorded in data sheet of the patients. 30 patients of subarachnoid haemorrhage were then selected for DSA. Angiography was performed after 4 weeks by DSA technique via a femoral arterial approach by two interventional neurologist blinded of CTA findings. Identification of aneurysmal sites and measurement of their size were done. Aneurysmal size d" $4 \mathrm{~mm}$ was considered as small, 5- $12 \mathrm{~mm}$ as medium and $>13 \mathrm{~mm}$ as large ${ }^{9}$. Biplanar DSA was used as the gold standard. The findings of CTA and DSA 
were directly compared to determine the sensitivity, specificity and accuracy of CTA.

\section{Analysis of data:}

Analysis of data was done with the help of computer by SPSS 16.0 program. Chi-square test was used as test of hypothesis. Mean, Standard deviation and Test of Validity were used for analysis.

\section{Results:}

The mean age of the patients having features of subarachnoid haemorrhage was $44.9 \pm 9.7$ years. Male female ratio was almost 1.5:1. All the study patients $(100 \%)$ had headache and vomiting and 19 patients (63.3\%) found unconscious. Signs of meningeal irritation were found in $23(76.7 \%)$ patients. Third cranial nerve palsy was present in $10 \%$ of the respondents. Regarding the presence of risk factors, $43.3 \%$ patients were smoker and $46.6 \%$ were hypertensive.

Among 10 small aneurysms detected on DSA, CTA incorrectly diagnosed 2 and overlooked 2 aneurysms. The sensitivity, specificity, accuracy, positive predictive value and negative predictive value of CTA in diagnosing small sized aneurysm were $60 \%, 100 \%, 86.7 \%, 100 \%$, 83.3\% respectively. Among 14 medium sized aneurysms identified on DSA, CTA missed 2 aneurysms. The sensitivity, specificity, accuracy, positive predictive value and negative predictive value of CTA in diagnosing medium sized aneurysm were $85.7 \%, 87.5 \%, 86.7 \%$, $85.7 \%, 87.5 \%$ respectively. CTA correctly identified all 6 large aneurysms detected on DSA. So, the sensitivity, specificity, accuracy, positive predictive value and negative predictive value of CTA in diagnosing large sized aneurysm were $100 \%$ in each component. Regarding the location, CTA correctly identified $73.4 \%$. $13.3 \%$ were incorrectly identified and $13.3 \%$ were missed. The sensitivity, accuracy and positive predictive value of CTA in the diagnosis of location of aneurysm is $73.3 \%, 73.3 \%$ and $100 \%$ respectively.

Table-I

Comparison between CTA and DSA for identification of the size of aneurysm

\begin{tabular}{llcccccc}
\hline \multirow{2}{*}{$\begin{array}{l}\text { Size of aneurysm } \\
\text { by CTA }\end{array}$} & \multicolumn{9}{c}{ Evaluated by DSA } & \multicolumn{2}{c}{$\mathrm{P}$} \\
& \multicolumn{2}{c}{ Small(n=10) } & \multicolumn{2}{c}{ Medium $(\mathrm{n}=14)$} & \multicolumn{2}{c}{ Large(n=6) } & value \\
& $\mathrm{n}$ & $\%$ & $\mathrm{n}$ & $\%$ & $\mathrm{n}$ & $\%$ & \\
\hline Small & 6 & 60.0 & 0 & 0.0 & 0 & 0.0 \\
Medium & 2 & 20.0 & 12 & 85.7 & 0 & 0.0 & 0.001 \\
Large & 0 & 0.0 & 0 & 0.0 & 6 & 100.0 \\
Missed & 2 & 20.0 & 2 & 14.3 & 0 & 0.0 \\
\hline
\end{tabular}

Table-II

Comparison between CTA and DSA for identification of small sized aneurysms.

\begin{tabular}{lccc}
\hline CTA & \multicolumn{2}{c}{ DSA } & Total \\
\cline { 2 - 3 } & Positive for Small size & Negative for Small size & \\
\hline Positive for Small size & 6 & 0 & 6 \\
Negative for Small size & 4 & 20 & 24 \\
\hline Total & 10 & 20 & 30 \\
\hline
\end{tabular}

Table-III

Comparison between CTA and DSA for identification of medium sized aneurysms.

\begin{tabular}{lccc}
\hline CTA & \multicolumn{2}{c}{ DSA } & Total \\
\cline { 2 - 4 } & Positive for medium size & Negative & for medium size \\
\hline Positive for medium size & 12 & 2 & 14 \\
Negative for medium size & 2 & 14 & 16 \\
\hline Total & 14 & 16 & 30 \\
\hline
\end{tabular}


Table-IV

Comparison between CTA and DSA for identification of large sized aneurysms.

\begin{tabular}{lccc}
\hline CTA & \multicolumn{2}{c}{ DSA } & Total \\
\cline { 2 - 4 } & Positive for large size & Negative for large size & \\
\hline Positive for large size & 6 & 0 & 6 \\
Negative for large size & 0 & 24 & 24 \\
\hline Total & 6 & 24 & 30 \\
\hline
\end{tabular}

Table-V

Comparison between CTA and DSA for identification of location of aneurysm

\begin{tabular}{lccccccccccccccc}
\hline $\begin{array}{l}\text { Location of } \\
\text { Aneurysm by CTA }\end{array}$ & \multicolumn{1}{c}{$\begin{array}{c}\text { Internal } \\
\text { carotid } \\
(\mathrm{n}=1)\end{array}$} & $\begin{array}{c}\text { Anterior } \\
\text { communi- } \\
\text { cating } \\
(\mathrm{n}=11)\end{array}$ & $\begin{array}{c}\text { Middle } \\
\text { cerebral } \\
(\mathrm{n}=8)\end{array}$ & $\begin{array}{c}\text { Posterior } \\
\text { communi } \\
\text { cating } \\
(\mathrm{n}=7)\end{array}$ & $\begin{array}{c}\text { Postero } \\
\text { inferior } \\
\text { cerebellar } \\
(\mathrm{n}=2)\end{array}$ & $\begin{array}{c}\text { Top of } \\
\text { basilar } \\
(\mathrm{n}=1)\end{array}$ & $\begin{array}{c}\text { Total } \\
\text { CTA }\end{array}$ \\
\hline Internal carotid & $\mathrm{n}$ & $\%$ & $\mathrm{n}$ & $\%$ & $\mathrm{n}$ & $\%$ & $\mathrm{n}$ & $\%$ & $\mathrm{n}$ & $\%$ & $\mathrm{n}$ & $\%$ & $\mathrm{n}$ & $\%$ \\
Anterior communicating & 1 & 100 & 0 & 0 & 0 & 0 & 1 & 14.3 & 0 & 0 & 0 & 0 & 2 & 6.7 \\
Middle cerebral & 0 & 0 & 9 & 81.8 & 0 & 0 & 1 & 14.3 & 0 & 0 & 0 & 0 & 10 & 33.3 \\
Posterior communicating & 0 & 0 & 1 & 9.1 & 8 & 100 & 0 & 0 & 0 & 0 & 0 & 0 & 9 & 30 \\
Postero inferior cerebellar & 0 & 0 & 0 & 0 & 0 & 0 & 2 & 28.6 & 1 & 50 & 0 & 0 & 3 & 10 \\
Top of basilar & 0 & 0 & 0 & 0 & 0 & 0 & 0 & 0 & 1 & 50 & 0 & 0 & 1 & 3.3 \\
Missed & 0 & 0 & 0 & 0 & 0 & 0 & 0 & 0 & 0 & 0 & 1 & 100 & 1 & 3.3 \\
\hline Total & 0 & 0 & 1 & 9.1 & 0 & 0 & 3 & 42.9 & 0 & 0 & 0 & 0 & 4 & 13.3 \\
\hline
\end{tabular}

\section{Discussion:}

The ideal examination for the detection and characterization of intracranial aneurysms should not only be non invasive, easy to perform, readily available and associated with only minor complications, but it also should depict aneurysms with high accuracy for successful surgical or endovascular treatment ${ }^{10}$. Also important are demonstration of arterial origin, surrounding vascular anatomy, orientation of sac with regard to the skull base, as well as accurate measurement and display of aneurysm sac and neck ${ }^{11}$. In the present study it was observed that the number of small, medium and large sized aneurysms were 10,14 and 6 respectively which was evaluated by DSA. Among 10 small sized aneurysm evaluated by DSA, CTA reported 6 as small, 2 as medium. The other 2 were missed by CTA. Among 14 medium sized aneurysm evaluated by DSA, CTA reported 12 as medium. The other 2 were missed by CTA. Six large aneurysms were evaluated $100 \%$ by both CTA and DSA. Four aneurysms were missed by CTA in which $20 \%$ were small and $14.3 \%$ were medium which was significant $(\mathrm{p}<0.05)$ regarding the identification of size of aneurysm by CTA and DSA. Dammert et al. $(2004)^{12}$ found in their study of 45 aneurysms, 6 small sized and 2 medium sized aneurysms were overlooked by CTA. All large aneurysm was identified by CTA.

Regarding the location of the aneurysm it was observed in this current study that 1 internal carotid, 11 anterior communicating, 8 middle cerebral, 7 posterior communicating, 2 postero inferior cerebellar and 1 top of basilar aneurysms were evaluated by DSA. But CTA detected those aneurysms in the following locations, in internal carotid 2, anterior communicating 10 , middle cerebral 9 , posterior communicating 3 , postero inferior cerebellar 
1 and in the top of basilar artery 1 aneurysm. CTA failed to localize 4 aneurysms. There was a mismatch in the location of 4 aneurysms on DSA and CTA. Of those 4, first one located at posterior communicating on DSA was located at internal carotid on CTA. Second one located at postero inferior cerebellar on DSA was noted at posterior communicating on CTA. Third one located at anterior communicating on DSA was located at middle cerebral on CTA. The location of the other aneurysm was noted at anterior communicating artery on CTA but was at the posterior communicating artery on DSA. Dammert et al. (2004) ${ }^{12}$ mentioned in their study that two aneurysms on the cavernous internal carotid artery, one P1 segment aneurysm, one posterior communicating artery aneurysm and one pericallosal artery aneurysm were overlooked on CTA which were actually identified on DSA. Peker et al. (2009) ${ }^{13}$ found in their study that there was a mismatch in the location of two aneurysms on DSA and MDCTA. One of these aneurysms, which was located at Pcom on DSA, was presumed to be located at the supraclinoid segment of ICA on MDCTA. The location of the other aneurysm was noted at the M1 bifurcation on MDCTA, but was at the M2 bifurcation on DSA.

It was observed in the present study that in the diagnosis of small sized aneurysms, sensitivity was $60 \%$, specificity $100 \%$, accuracy $86.7 \%$, positive predictive value $100 \%$ and negative predictive value $83.3 \%$ of CTA. Similarly, in the diagnosis of medium sized aneurysms, sensitivity was $85.7 \%$, specificity $87.5 \%$, accuracy $86.7 \%$, positive predictive value $85.7 \%$ and negative predictive value 87.5 $\%$ of CTA. The sensitivity, specificity, accuracy, positive predictive value and negative predictive value of CTA in diagnosing large sized aneurysm were $100 \%$ in each component. Ogawa et al. (1996) ${ }^{14}$ reported a sensitivity of only $24 \%$ to aneurysms $<5 \mathrm{~mm}$ on CTA. However, Korogi et al. (1999) ${ }^{9}$ reported CTA sensitivity as 64\%, 83\%, 95\% and 100\% in diagnosis of very small, small $(3-4 \mathrm{~mm})$, medium (5-12 $\mathrm{mm})$, and large $(>13 \mathrm{~mm})$ aneurysms respectively which is very much consistent with the results of the present study. Dammert et al. (2004) ${ }^{12}$ found the overall sensitivity, specificity, accuracy, positive predictive value, negative predictive value of CTA to detection rate (\%) of aneurysms were $89.5 \%, 83.3 \%, 88.6 \%, 97.2 \%$ and $56.1 \%$ respectively. In that study sensitivity of CTA was $83.3 \%, 90.6 \%$ and $100 \%$ for small $(<4 \mathrm{~mm})$, medium $(5-12 \mathrm{~mm})$ and large $(>13 \mathrm{~mm})$ aneurysms which are almost consistent with the current study.

In the diagnosis of location of aneurysm it was observed in this study that sensitivity $73.3 \%$, accuracy $73.3 \%$ and positive predictive value $100 \%$ of CTA. White et al., (2001) ${ }^{15}$ had found CTA sensitivity $69 \%$ and specificity $80 \%$ in detection of intracranial aneurysms, which support the current study.

\section{Conclusion:}

Computed Tomographic Angiography is less sensitive, specific and accurate than Digital Subtraction Angiography in detecting small and medium sized aneurysms. But it correlated perfectly with DSA in detection of large aneurysms. The performance of CTA in identification of aneurysmal site is also lesser than DSA. Hence, DSA remains the standard technique for evaluation of aneurysmal SAH.

\section{References:}

1. Ropper AH, Samuels MA. eds. Cerebrovascular disease in Adams and Victor's principles of neurology. $9^{\text {th }}$ ed. USA: McGraw- Hill; 2009: p.808-9.

2. Longmore, Murrey, Wilkinson I, Turmezei T, Cheung CK. Oxford handbook of clinical medicine, $7^{\text {th }}$ ed. Oxford: Oxford University Press; 2007 : p. 841 .

3. Linn FH, Rinkel GJ, Algra A, Van Gijn J. Headache characteristics in Sub arachnoid hemorrhage and benign thunderclap headache. Journal of Neurol Neurosurg Psychiatr 1998; 65: 7.

4. Feigin VL, Rinkel GJ, Lawes CM, et al. Risk factors for subarachnoid hemorrhage: an updated systematic review of epidemiological studies. Stroke 2005; 36(12): 2773-80.

5. David WA, Timothy MC et al. eds. Oxford handbook of Medicine, $4^{\text {th }}$ ed. volume 3. Oxford: Oxford University Press; 2003: p.1032-4.

6. Chan JW, Hoyt WF, Ellis WG, Gress D. Pathogenesis of acute mono ocular blindness from leaking anterior communicating artery aneurysms: report of ix cases. Neurology 1997; 48: 680-3. 
7. Yoon DY, Kim KJ, Chol CS et al. Detection and characterization of intracranial aneurysms with 16- channel multidetector row CT angiography: a prospective comparison of volume rendered images and digital subtraction angiography. Am J Neuroradiol 2007; 28; 60-7.

8. Uysal E, Yanbulođlu B, Ertürk M, Kýlýnç BM, Bapak M. Spiral CT angiography in diagnosis of cerebral aneurysms of cases with acute subarachnoid hemorrhage. Diagn Intervent Radiol 2005; 11:77-82.

9. Korogi Y, Takahashi M, Katada K, et al. Intracranial aneurysms: detection with threedimensional CT angiography with volume rendering-comparison with conventional angiographic and surgical findings. Radiology 1999; 211: 497-506.

10. Jayarman MV, Mayo Smith W, Tung GA, et al. Detection of intracranial aneurysms: multidetector row CT angiography compared with DSA. Radiology 2004; 230: 510-8

11. Karamessini MT, kagadis GC, Petsas T et al. CT angiography with three dimensional technique for the early diagnosis of intracranial aneurysm, comparison with intra-arterial DSA and the surgical findings, Eur J Radiol 2004; 49: 212-23.

12. Dammert $\mathrm{S}$, Krings $\mathrm{T}$, Moller-Hartmann $\mathrm{W}$, Ueffing E, Hans FJ, Willmes K, et al. Detection of intracranial aneurysms with multislice CT: comparison with conventional angiography. Neuroradiology 2004; 46: 427-34.

13. Peker A, Üstüner E, Özkavukcu E, Sancak T. Performance analysis of 8-channel MDCT angiography in detection, localization, and sizing of intracranial aneurysms identified on DSA. Diagn Intervent Radiol 2009; 15: 81-5.

14. Ogawa T, Okudera T, Noguchi K, et al. Cerebral aneurysms. Evaluation with three-dimensional CT angiography. Am J Neuroradiol 1996; 17: 447-54.

15. White P, Teasdale E, Wardlaw J, Easton V. Intracranial aneurysms: CT Angiography and MR Angiography for detection-pro-spective blinded comparison in a large patient cohort. Radiology 2001; 219: 739-49. 